\author{
С.В. Романов, О.П. Абаева, Г.Ю. Смирнова \\ ФБУЗ «Приволжский окружной медицинский центр» ФМБА России, \\ 603001 , Россия, Нижний Новгород, Нижневолжская набережная, д. 2 \\ Контактная инооомация: Сергей Владимирович Романов, канд. мед. наук, \\ директор Приволжского окружного медицинского центра ФМБА России, e-mail: info @ pomc.ru \\ Дата поступления статьи: 21.12.2017 \\ Принята в печать: 29.01.2018
}

В статъе проведен анализ системъ трансплантаиии органов региона с иелью определения путей оптимизации использования донорского ресурса. Авторами установлено, что наибольшую трудность представляют те мероприятия програмлы, успех реализации которых зависит от отношения медицинских работников и населения региона. В связи с этим проведен анкетнъй опрос, результатъ которого свидетельствуют о недостаточном уровне инбормированности врачей и населения о роли трансплантологии в современной медииине и законодательстве в данной сфере отночений. Авторы приходят к заключению о важности инбормационно-разъяснительной работы и популяризации програмль посмертного донорства среди медицинских работников и всех групп населения для оптимизации использования донорского ресурса региона.

Ключевые слова: трансплантация органов, донорский ресурс

Романов С.В., Абаева О.П., Смирнова Г.Ю. Пути совершенствования использования донорского ресурса в Нижегородской области. Трансплантология. 2018;10(1):15-22. DOI:10.23873/2074-0506-2018-10-1-15-22

\title{
Ways to improve the use of donor resources in the Nizhny Novgorod Region
}

\author{
S.V. Romanov, O.P. Abaeva, G.Yu. Smirnova \\ Volga District Medical Center \\ 2 Nizhnevolzhskaya nab., Nizhny Novgorod 603001, Russia \\ Correspondence to: Sergey V. Romanov, Cand. Med. Sci., Director of the Volga District Medical Center, \\ e-mail: info@ pomc.ru \\ Received: 21 December 2017 \\ Accepted for publication: 29 January 2018
}

The article analyzes the system of organ transplantation in the Nizhny Novgorod Region in order to determine the ways to optimize the use of donor resource. The authors found that the most difficult are the program activities, the success of which depends on the attitude of health care employees and the population of the region. In this regard, a questionnaire survey was conducted; its results indicated a lack of awareness among doctors and the public about the transplantation role in modern medicine and the legislation in this sphere of relations. The authors come to the conclusion on the importance of the outreach and promotion of the posthumous organ donation program among health care employees and all population groups to optimize the use of donor resource of the region.

Keywords: organ transplantation, donor resource

Romanov S.V., Abaeva O.P., Smirnova G.Yu. Ways to improve the use of donor resources in the Nizhny Novgorod Region. Transplantologiya . The Russian Journal of Transplantation. 2018;10(1):15-22. (In Russian). DOI:10.23873/2074-0506-2018-10-1-15-22

\section{Введение}

Согласно данным Регистра Российского трансплантологического общества, в 2017 г. данный вид высокотехнологичной медицинской помощи оказывался населению нашей страны в 45 медицинских организациях, 1/3 которых расположена в Москве, Санкт-Петербурге и Московской области. Таким образом, лишь 20 нестоличных регионов страны располагают центрами трансплантации органов и тканей, причем в половине из них осуществляется только трансплантация почки [1]. При этом, как неоднократно отмечалось, в каждом из регионов сформировалась своя система взаимоотношений между медицинскими организациями-участниками программы донор- 
ства и трансплантации [2-6]. Одним из регионов страны, в котором систематически осуществляется трансплантация органов человека, является Нижегородская область. Важно подчеркнуть, что особенностью данного региона являются традиционно неблагоприятные, по сравнению с Российской Федерацией, демографические показатели и в первую очередь высокий уровень общей смертности. Таким образом, проблема спасения жизней нижегородцев остается крайне актуальной задачей для руководства области. На протяжении более 10 лет начиная с 2006 г. единственной медицинской организацией, обеспечивающей доступность для нижегородцев и жителей соседних субъектов РФ (Республики Чувашия, Кировской области) трансплантации органов как вида высокотехнологичной медицинской помощи, является Федеральное бюджетное учреждение здравоохранения «Приволжский окружной медицинский центр» Федерального медико-биологического агентства (ФБУЗ ПОМЦ ФМБА России), где ежегодно выполняют 30-40 операций по пересадке органов (почки, печени, поджелудочной железы). Безусловно, материально-техническая база и кадровый потенциал ФБУЗ ПОМЦ ФМБА России позволяют осуществлять гораздо большее количество операций, но, как и во всем мире, основным фрактором, лимитирующим количество спасенных реципиентов, служит донорский ресурс [2]. Так, донорская активность в Нижегородской области составляет 3,3 на 1 млн человек, что практически соответствует среднему уровню данного показателя по стране, но является достаточно низкой цифрой для региона, где реализуется программа трансплантации органов.

В связи с вышеизложенным целью нашего исследования стало определение путей совершенствования использования донорского ресурса Нижегородской области.

Для достижения поставленной цели нами были сорормулированы следующие задачи:

- исследовать систему взаимодействия между участниками нижегородской региональной программы донорства и трансплантации органов и установить наиболее проблемные точки соприкосновения при организации посмертного донорства;

- выявить и исследовать медико-социологические фракторы, оказывающие влияние на реализацию региональной программы донорства в аспекте посмертного донорства.
Материал и методы

В качестве баз исследования нами были использованы: ФБУЗ ПОМЦ ФМБА России, 6 больниц - донорских баз региона (согласно приказу Министерства здравоохранения Нижегородской области, в качестве донорских баз определена 21 медицинская организация, из которой реально участвуют в донорстве только 6; в нашем исследовании участвовали 3 активные и 3 неактивные донорские базы), Нижегородский государственный университет им. Н.И. Лобачевского (ННГУ) и Grinnell college, Iowa, USA (одно из старейших учебных заведений США, в котором проводят обучение по программам бакалавриата). Материалами исследования послужили:

- учетно-отчетная документация центра донорства ФБУЗ ПОМЦ ФМБА России по 327 случаям выезда донорских бригад за 20092016 гг.;

- данные анкетного опроса 266 врачей донорских баз (173 врача активных и 93 - неактивных баз). Респонденты составили практически равные группы по гендерному признаку (женщины $50,7 \pm 3,1 \%$ ). В исследовании приняли участие врачи всех возрастных групп (20-24 года $-7,5 \pm$ $1,6 \%, 25-29$ лет $-13,5 \pm 2,1 \%, 30-34$ года $-12,0 \pm$ $2,0 \%, 35-39$ лет $-7,9 \pm 1,7 \%, 40-44$ года $-15,4 \pm$ $2,2 \%, 45-49$ лет $-12,4 \pm 2,0 \%, 50-54$ года $-6,4 \pm$ $1,5 \%, 55-59$ лет $-9,8 \pm 1,8 \%, 60-64$ года $-7,1 \pm$ 1,6\%, 65-69 лет $-4,1 \pm 1,2 \%, 70-74-3,9 \pm 1,2 \%)$, а также различных врачебных специальностей: врачи анестезиологи-реаниматологи - 10,5 \pm $1,9 \%)$, хирурги - 20,3 $\pm 2,5 \%$, терапевты, кардиологи $-20,3 \pm 2,5 \%$, неврологи $-5,6 \pm 1,4 \%$ и др.

- данные опроса 168 студентов I-II курсов немедицинских фракультетов ННГУ и 105 Grinnell college.

Опрос студентов проводили по идентичным анкетам на русском и английском языках. Обработку данных осуществляли при помощи программы Minitab, а оценку статистической значимости - на основании средней ошибки экстенсивных показателей при сравнительном анализе коэффициентов Стъюдента (t). Разница в значении показателей оценивалась как статистически значимая при $\mathrm{t}$, превышающем или равном 2 . 


\section{Результаты исследования}

В Нижегородской области за более чем 10-летний период сложилась достаточно простая, по сравнению с другими регионами, система взаимодействия между участниками региональной программы, включающая центры донорства и трансплантации, являющиеся структурными подразделениями ФБУЗ ПОМЦ ФМБА России, и донорские базы (рис. 1).

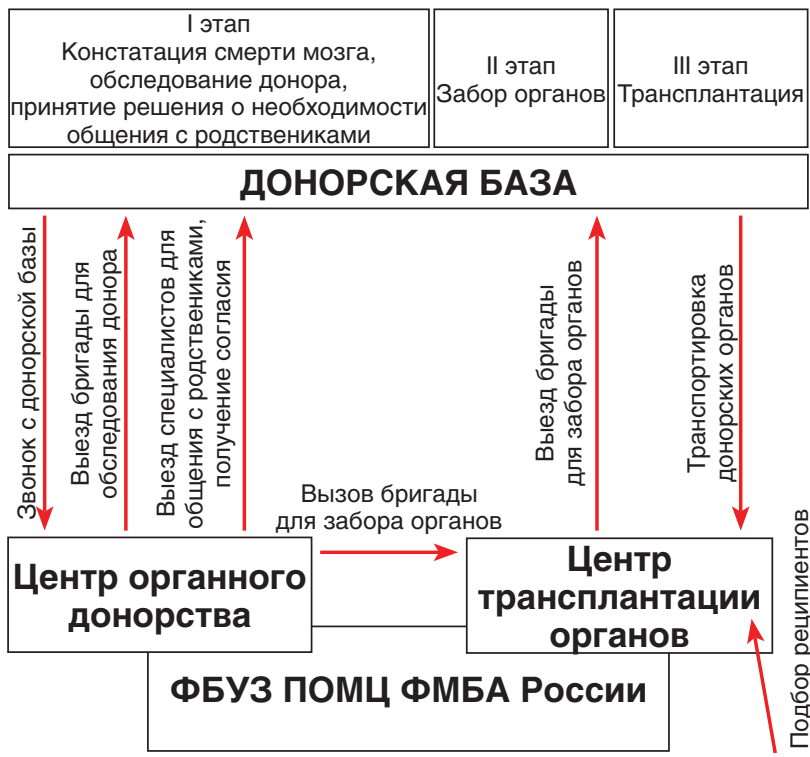

Рис. 1. Система взаимодействия между участниками программы трансплантации органов в Нижегородской области

Fig. 1. The System of interactions between the participants of Organ Transplantation Program in the Nizhny Novgorod Region

Процесс пересадки органа включает три традиционных этапа. Первый этап начинается с сообщения специалистов донорской базы сотрудникам центра органного донорства о наличии потенциального донора. Бригада врачей центра донорства выезжает для предварительного обследования донора, параллельно комиссия врачей донорской базы осуществляет процедуру констатации смерти мозга. На этом же этапе решается вопрос о необходимости получения согласия родственников донора на забор органов.
Согласие родственников испрашивается в 2 случаях: при нахождении в описываемый период в медицинской организации родственников донора, проявляющих активность, и при наличии подобного требования у администрации донорской базы во избежание возможных конфликтов. В остальных случаях при отсутствии информации о прижизненном волеизъявлении потенциального донора, содержащего его негативное отношение к посмертному донорству, согласие родственников не испрашивается. Таким образом, решение о необходимости оформления согласия родственников донора принимается коллегиально специалистами донорской базы и центра донорства. Для осуществления данной процедуры на территорию донорской базы выезжают специально подготовленные специалисты центра донорства.

На протяжении периода с 2009 по 2016 г. нами отмечена тенденция к снижению количества первичных выездов донорских бригад при сохранении числа актуальных ${ }^{1}$ доноров (рис. 2). Однако крайне негативной характеристикой является сохранение высокого числа приемлемых доноров, не ставших реальными донорами вследствие отказа родственников от забора органов. Ретроспективный анализ документации по результатам выезда донорских бригад показал, что при обращении к родственникам приемлемого донора согласие было получено в половине случаев. При этом наиболее значимым фрактором, повлекшим отрицательный ответ родственников, являлась беседа со священнослужителем, представителем Русской Православной Церкви, или каким-либо знакомым медицинским работником.

На втором этапе после получения согласия родственников или при принятии решения об отсутствии необходимости такового информация о наличии реального донора передается в центр трансплантации, откуда выезжает бригада трансплантологов, параллельно идет подбор реципиента (реципиентов). На третьем этапе осуществляется трансплантация органа (органов) реципиенту (реципиентам).

Таким образом, значимыми оракторами, влияющими на повышение эфффективности использования донорского ресурса региона, являются:

\footnotetext{
${ }^{1}$ Использована терминология проекта Федерального закона «О донорстве органов человека и их трансплантации». https://www. rosminzdrav.ru/documents/8145: потенциальный донор - донор, в отношении которого начата и проводится процедура констатации смерти (биологической смерти или смерти мозга) в соответствии с законодательством Российской Федерации в сфере охраны здоровья; приемлемый донор - потенциальный донор, в отношении которого констатирована смерть и установлено отсутствие медицинских противопоказаний для использования его органов в целях трансплантации; реальный донор - приемлемый донор, в отношении которого имеются предусмотренные настоящим Федеральным законом документально оформленные правовые и медицинские основания, позволяющие изъять из его тела донорские органы в целях трансплантации; актуальный донор - реальный донор, от которого трансплантирован по меньшей мере один донорский орган реципиенту, нуждающемуся в лечении методом трансплантации донорских органов.
}

\section{ТРАНСПЛАНтоЛОГИЯ 1'2018 том 10}

TRANSPLANTOLOGIYA 1 '2018 vol. 10 The Russian Journal of Transplantation 


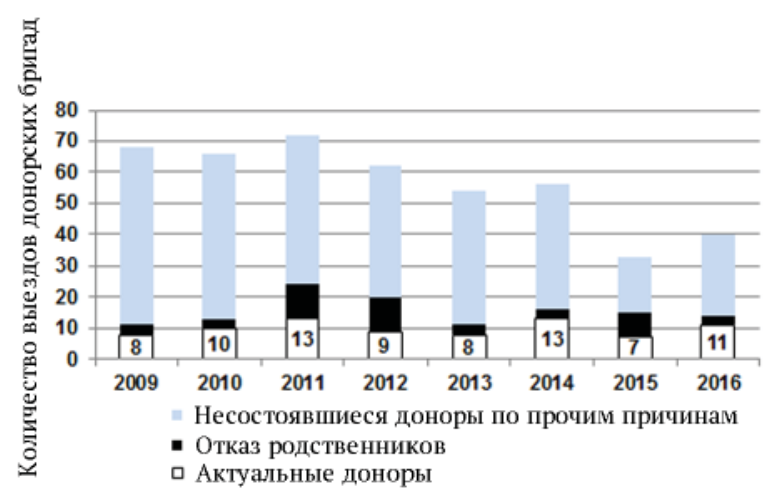

Рис. 2. Динамика количества выездов донорских бригад и количества актуальных посмертных доноров (абсолютные числа)

Fig. 2. The number of trips undertaken by the donor coordination teams and the number of actual posthumous donors (absolute numbers); changes over time

- отношение врачей донорских баз к программе трансплантации, поскольку оно служит ключевым моментом для начала всей процедуры;

- отношение населения, определяющее как прижизненное волеизъявление донора, так и посмертное оформление согласия (или отсутствие отказа) родственников для забора органов;

- позиция врачебного сообщества по вопросам донорства органов, безусловно, влияющая на отношение населения к данной проблеме.

В связи с вышеизложенным нами был проведен анкетный опрос врачей активных и неактивных донорских баз по вопросам их профрессионального и личного отношения к донорству и трансплантации органов человека. Как показали результаты исследования, большинство опрошенных $(80,1 \pm 2,4 \%)$ заявили о том, что они в достаточном, по их мнению, объеме инорормированы о современных клинических возможностях трансплантации органов человека. При этом нами не было установлено статистически значимого различия значения данного показателя для врачей активных и неактивных донорских баз.

Независимо от места работы 88,7 $\pm 1,9 \%$ врачей считают, что развитие данного вида медицинской помощи в регионе является важной задачей для спасения жизней пациентов, в то же время каждый десятый опрошенный (11,3 \pm $1,3 \%)$ придерживается мнения о том, что в условиях современной экономической ситуации развитие трансплантологии оринансово не оправдано. Интересно отметить, что при достаточно высокой субъективной оценке своих знаний о современных клинических возможностях трансплантологии $1 / 3$ врачей $(38,7 \pm 2,9 \%)$ затруднились ответить, дали бы они при возникновении такой необходимости свое согласие на операцию по пересадке органов и поддержали бы проведение подобного вмешательства для своих близких.

Согласно данным опроса, лишь $11,1 \pm 1,3 \%$ врачей донорских баз участвуют в программе трансплантации, руководствуясь пониманием значимости этой работы, в 59,3 $\pm 3,0 \%$ случаев ведущую роль играют организационно-распорядительные методы администрации, для остальных врачей $(29,6 \pm 2,8 \%)$ имеют значение оба фрактора. При этом почти половина респондентов $(44,2 \pm 3,1 \%)$ отметили, что, по их мнению, работа, связанная с трансплантацией органов, встречает поддержку в коллективе, $1 / 5$ часть врачей $(20,3 \pm 2,5)$ воспринимают эту проблему с безразличием, $4,2 \pm 1,2 \%$ сталкивались с негативным отношением коллег. В остальных случаях $(31,3 \pm 2,9 \%)$ вопрос об отношении врачебного коллектива к трансплантации органов вызвал затруднение у респондентов.

В случае выявления потенциального донора только $10,9 \pm 1,9 \%$ опрошенных независимо от активности их медицинской организации как донорской базы самостоятельно свяжутся с трансплантологами, $13,9 \pm 2,2 \%$ врачей предварительно обсудят такую возможность с родственниками донора, 44,0 \pm 3,0\% сообщат представителям администрации больницы, 27,1 $\pm 2,1 \%$ ничего не предпримут.

Нам не удалось также установить статистически значимых различий в уровне информированности врачей активных и неактивных донорских баз о нормативно-правовых основах трансплантации. Результаты показали, что только 44,3 \pm $3,1 \%$ опрошенных в полной мере располагают инфрормацией о норме российского законодательства, регламентирующей презумпцию согласия населения на посмертный забор органов и лишь $18,6 \pm 2,4 \%$ данную норму поддерживают, каждый пятый респондент $(22,8 \pm 2,6 \%)$ считает забор органов возможным только при наличии прижизненного согласия донора.

Больше половины респондентов $(58,6 \pm 3,0 \%)$ считают, что забор органов возможен только при наличии прижизненного согласия донора или согласия родственников, полученного после смерти донора. При этом нами установлено, что такая общественная позиция в большей, статистически значимой степени характерна для врачей неактивных донорских баз (66,6 \pm 4,9\%), чем сотрудников организаций, активно участвующих в трансплантации $(53,2 \pm 3,8 \% ; \mathrm{t}=2,2)$. 


\section{AGTUAL ISSUES OF TRANSPLANTATION}

Нами было также исследовано личное отношение врачей к участию в программе донорства: менее половины опрошенных $(44,7 \pm 3,1 \%)$ сочли бы возможным разрешить использование своих органов в случае гибели в медицинских целях, $15,1 \pm 2,2 \%$ ответили отказом, остальные затруднились ответить. Также половина опрошенных согласилась бы в случае такого предложения оформить прижизненное согласие на посмертное донорство органов. Статистически значимых различий между сотрудниками активных и неактивных донорских баз установлено не было.

Исследование отношения населения к проблемам трансплантации проводили по данным сравнительного анализа однородных социальных групп населения, различающихся по формированию в условиях нормативного закрепления презумпции согласия или необходимости обязательного прижизненного получения согласия донора. Нами были опрошены студенты одинаковых возрастных групп, обучающиеся по дисциплинам, не связанным с медициной, в региональных вузах России и США. Выбор именно студентов в качестве объектов исследования определен преимуществом влияния на их социальную позицию фракторов окружающей среды над личным опытом. Результаты опроса по вопросам анкеты, в которых было установлено статистически значимое различие между ответами российских и американских респондентов, представлены в табл. 1 .

Как показали результаты опроса, о клинических возможностях трансплантологии абсолютно не осведомлены $20,8 \pm 4,0 \%$ студентов американского колледжа, что статистически значимо ниже аналогичного показателя у студентов нижегородского вуза $(36,3 \pm 3,7 \% ; \mathrm{t}=2,7)$. При этом $1 / 4$ американских студентов $(25,7 \pm 4,2 \%)$ уже сталкивались с осуществлением трансплантации близким им людям, у российских студентов данный показатель составил 7,1 $\pm 2,0 \%(\mathrm{t}=4,0$, статистически значимо). Личное отношение американских студентов к трансплантации как методу лечения при наличии необходимости определено весыма четко: подавляющее большинство $(85,7 \pm$ $3,4 \%$ ) считают данный вид медицинского вмешательства обычной клинической практикой и только 13,3 \pm 3,3\% не приемлют трансплантацию для себя и своих близких. Доля студентов, затруднившихся при ответе на данный вопрос, не имела статистической значимости. Среди российских студентов статистически значимо меньшая часть выразила бы согласие на применение трансплантации себе и своим близким людям (55,4 $\pm 3,8 \%$;
Таблица 1. Параметры опроса студентов, обучающихся по программам бакалавриата в России и США, в которых были установлены статистически значимые различия (\% опрошенных)

Table 1. The survey parameters demonstrating significant differences between the students studying under the bachelor's degree programs in Russia and the USA (\% of responders)

\begin{tabular}{|c|c|c|}
\hline $\begin{array}{c}\text { Параметры опроса, в которых } \\
\text { установлены статистически } \\
\text { значимые различия }\end{array}$ & $\begin{array}{l}\text { Доля } \\
\text { студентов, } \\
\text { Россия }\end{array}$ & $\begin{array}{l}\text { Доля } \\
\text { студентов, } \\
\text { США }\end{array}$ \\
\hline $\begin{array}{l}\text { Родственники или близкие люди } \\
\text { сталкивались с необходимостью } \\
\text { трансплантации органов }(\mathrm{t}=4,0)\end{array}$ & $7,1 \%$ & $25,7 \%$ \\
\hline $\begin{array}{l}\text { Абсолютно не располагают инфор- } \\
\text { мацией о клинических возможно- } \\
\text { стях трансплантологии }(t=2,7)\end{array}$ & $36,3 \%$ & $20,8 \%$ \\
\hline \multicolumn{3}{|c|}{ В случае клинической необходимости: } \\
\hline $\begin{array}{l}\text { считают возможным трансплан- } \\
\text { тацию органа себе и близким } \\
(\mathrm{t}=5,7)\end{array}$ & $55,4 \%$ & $85,7 \%$ \\
\hline $\begin{array}{l}\text { затрудняются в решении вопро- } \\
\mathrm{ca}(\mathrm{t}=10,5)\end{array}$ & $42,2 \%$ & $1,0 \%$ \\
\hline $\begin{array}{l}\text { высказались бы против транс- } \\
\text { плантации }(\mathrm{t}=3,1)\end{array}$ & $2,4 \%$ & $13,3 \%$ \\
\hline \multicolumn{3}{|c|}{ Посмертный забор органов может осуществляться: } \\
\hline $\begin{array}{l}\text { только при наличии прижизнен- } \\
\text { ного согласия донора }(t=7,3)\end{array}$ & $69,0 \%$ & $27,6 \%$ \\
\hline $\begin{array}{l}\text { при наличии прижизненного со- } \\
\text { гласия донора или родственни- } \\
\text { ков после смерти донора }(t=4,8)\end{array}$ & $25,6 \%$ & $59,0 \%$ \\
\hline $\begin{array}{l}\text { независимо от согласия донора } \\
\text { и его родственников }(t=2,1)\end{array}$ & $5,4 \%$ & $13,4 \%$ \\
\hline $\begin{array}{l}\text { готовы офрормить согласие на } \\
\text { посмертное донорство }(t=9,7)\end{array}$ & $44,1 \%$ & $90,5 \%$ \\
\hline
\end{tabular}

$\mathrm{t}=5,7)$. Однако наибольший интерес, по нашему мнению, представляет группа затруднившихся при ответе, которая составила $42,2 \pm 3,8 \%$.

Анализ ответов респондентов в аспекте необходимости получения согласия на забор органов показал, что большинство $(69,0 \pm 3,6 \%)$ российских студентов придерживаются мнения о возможности посмертного донорства только при наличии прижизненного согласия самого донора. Доля таких респондентов среди американских студентов оказалась статистически значимо ниже и составила 27,6 $\pm 4,4 \%$; $=7,3$ ). Возможность учета мнения родственников при решении вопроса о посмертном заборе органов поддерживают $25,6 \pm 3,4 \%$ российских участников опроса и 59,0 $\pm 5,7 \%$ - американских $(\mathrm{t}=4,8$, статистически значимо). Позиции презумпции согласия придерживаются $5,4 \pm 1,7 \%$ российских 
студентов и 13,4 $\pm 3,3 \%$ - американских $(\mathrm{t}=2,1$, статистически значимо).

В настоящее время готовы подписать согласие на участие в программах посмертного донорства $44,1 \pm 3,8 \%$ российских участников опроса. Аналогичный статистически значимо более высокий показатель для американцев составил $90,5 \pm 2,9 \%(\mathrm{t}=9,7)$. При этом нами установлено единообразие фракторов, влияющих на волеизъявление студентов, независимо от страны проживания: ведущей причиной содействия программам посмертного донорства для них является инорормация о человеке, жизнь которого зависит от принятого донором решения $(52,6 \pm 3,9 \%$ российских студентов, 59,0 \pm 4,8\% - американских; $\mathrm{t}=1,0)$. На втором месте находятся также не имеющие статистической значимости фракторы фринансовой мотивации $(35,4 \pm 3,7 \%$ российских участников опроса, $37,1 \pm 4,6 \%$ - американских; $\mathrm{t}=0,3)$. Третье место заняло мнение представителя религиозной конфессии, которое важно для $11,3 \pm 2,4 \%$ российских респондентов и $14,3 \pm$ $3,4 \%$ - американских ( $\mathrm{t}=0,7$, статистически незначимо). Результаты опроса по вопросам анкеты, в которых было установлено статистически значимое различие между ответами российских и американских респондентов, представлены в табл. 2.

Таблица 2. Параметры опроса студентов, обучающихся по программам бакалавриата в России и США, в которых не было установлено статистически значимых различий (\% опрошенных)

Table 2. The survey parameters demonstrating no significant differences between the students studying under the bachelor's degree programs in Russia and the USA (\% of responders)

\begin{tabular}{l|c|c|}
$\begin{array}{l}\text { Параметры опроса, в которых } \\
\text { не установлены статистически } \\
\text { значимые различия }\end{array}$ & $\begin{array}{c}\text { Доля } \\
\text { студентов, } \\
\text { Россия }\end{array}$ & $\begin{array}{c}\text { Доля } \\
\text { студентов, } \\
\text { США }\end{array}$ \\
$\begin{array}{l}\text { При принятии решения об офоромлении согласия на по- } \\
\text { смертное донорство органов имело бы значение: }\end{array}$ \\
\hline $\begin{array}{l}\text { мнение представителя религи- } \\
\text { озной конфессии }\end{array}$ & $11,3 \%$ & $14,3 \%$ \\
\hline $\begin{array}{l}\text { факторы фониансовой мотива- } \\
\text { ции }\end{array}$ & $34,5 \%$ & $37,1 \%$ \\
\hline $\begin{array}{l}\text { информация о людях, которых } \\
\text { можно спасти }\end{array}$ & $25,6 \%$ & $59,0 \%$ \\
\hline
\end{tabular}

обсуждение

Таким образом, результаты нашего исследования свидетельствуют о том, что в сложившейся системе взаимодействия между участниками программы регионального донорства в
Нижегородской области в аспекте посмертного донорства наиболее проблемными являются мероприятия, эфрфективность которых определяется отношением к донорству медицинских работников и населения. При этом опрошенные нами специалисты клинических баз занимают настороженно-избегательную позицию по вопросу участия в программе донорства, что в первую очередь связано с недостаточным объемом предоставляемой им информации о клинических успехах и нормативно-правовом поле трансплантологии в России $(38,7 \pm 2,9 \%$ врачей не уверены в целесообразности операции по пересадке органов при наличии клинических показаний, только $44,3 \pm 3,1 \%$ опрошенных в полной мере располагают инорормацией о презумпции согласия населения на посмертный забор органов). Соответственно ведущим фрактором, влияющим на активность работы донорской базы, является указание администрации больницы. Наиболее тревожным фрактором, на наш взгляд, является личное пассивное отношение врачей к программам донорства: доля врачей, согласных выступить в качестве посмертных доноров, оказалась идентичной такому показателю у студентов, т.е. позиция медицинского работника с высшим образованием аналогична таковой у обывателя, не имеющего отношения к медицине.

Данные опроса студентов показали важность общественной среды для фрормирования у человека позитивного отношения к программам донорства. Американские студенты выросли в обществе, где клиническая и юридическая составляющие трансплантологии стали обычной нормой жизни: каждый четвертый опрошенный американец каким-то образом сталкивался с данной проблемой, подавляющее большинство из них считают трансплантацию органов допустимой клинической практикой, и, самое главное, практически отсутствуют неопределившиеся по данному вопросу. Среди российских студентов, наоборот, превалирует группа затрудняющихся ответить на вопрос о допустимости трансплантации органов для себя и своих близких при необходимости. Американские студенты четко поддерживают норму своего законодательства, российские - наоборот, выступают преимущественно против принципа отечественного закона. Нам показалось интересным, что российские студенты условием забора органов преимущественно считают согласие только самого донора, т.е. не высказывают доверия по данному вопросу даже родственникам. Мы считаем, что причиной 


\section{АКТУАЛЬНЫЕ ВОПРОЯЫ НЛИНИЧЕНКОЙ ТРАНЯППАНТОЛОГИИ}

\section{AGTUAL ISSUES OF TRANSPLANTATION}

вышеизложенного также служит недостаточный уровень информированности респондентов о юридических гарантиях безопасного посмертного донорства. При этом ведущим фрактором, влияющим на позицию населения изучаемой социальной группы в аспекте возможности оформления согласия на посмертный забор органов, является инорормационно-разъяснительная работа о гуманности трансплантологии и ее роли в спасении жизней людей.

\section{Заключение}

Мы считаем, что обязательным условием дальнейшего развития программы трансплантации органов и оптимизации использования донорского ресурса в Нижегородской области является инорормационная работа, направленная на популяризацию донорства, которую необходимо проводить как в профессиональной медицинской среде, так и во всех социальных группах населения.
Выводы

1. В настоящее время все мероприятия по организации посмертного органного донорства в Нижегородской области осуществляются трансплантологами при полном отсутствии поддержки иных заинтересованных сторон. Пассивнонастороженная позиция врачей, в первую очередь - администрации больниц, является причиной ограничения возможностей использования донорского ресурса: реально участвуют в реализации программы донорства менее $1 / 3$ донорских баз, регламентированных приказом территориального органа управления здравоохранением. Негативное отношение населения к донорству органов, сформировавшееся, в том числе и за счет отсутствия поддержки трансплантологии представителями религиозных организаций, приводит к значимым потерям актуальных доноров: в течение ряда лет число несостоявшихся по причине отказа родственников доноров было практически идентично актуальным.

2. Важнейшим медико-социологическим фрактором, определяющим успех реализации региональной программы посмертного донорства, является уровень инорормированности как населения, так и медицинских работников о юридической безопасности и гуманности трансплантологии как вида медицинской помощи.

КОНФЛИКТ ИНТЕРЕСОВ. АвторЫ ЗаЯВЛЯЮТ Об ОТСутСТвИИ КОНФЛИКта ИНтересов. CONFLICT OF INTERESTS. Authors declare no conflict of interest.

ФИНАНСИРОВАНИЕ. ИсСЛЕДОВаНИе ПрОВОДИЛОСЬ без спОНСорСКоЙ подДерЖки. FINANCING. The study was performed without external funding. 


\section{АКТУАЛЬНЫЕ ВОПРОЯЫ НЛИНИЧЕВКОЙ ТРАНЯПЛАНТОЛОГИИ}

\section{AGTUAL ISSUES OF TRANSPLANTATION}

\section{Литература}

1. Готье С.В., Хомяков С.М. Донорство и Федерации в 2016 году. IX сообщение регистра Российского трансплантологического общества. Вестник трансплантологии и искусственных органов. 2017;19(2):6-26. DOI:10.15825/19951191-2017-2-6-26.

2. Виноградов В.Л. Актуальные вопросы Трансплантология. 2013;(4):15-23. трансплантация органов в Российской органного донорства. Введение. Лекция

3. Минина М.Г. О некоторых аспектах организации органного донорства. Вестник трансплантологии и искусственных органов. 2010;12(3):81-88. DOI:10.15825/1995-1191-2010-3-81-88

4. Миронов А.А., Яремин Б.И., Колсанов А.В. и др. Органное донорство и трансплантационная координация в Самарской области: особенности региональной модели. Вестник трансплантологии и искусственных органов. 2015;17(2):140-143. DOI:10.15825/19951191-2015-2-140-143

\section{References}

1. Gautier S.V., Khomyakov S.M. Organ donation and transplantation in the Russian Federation in 2016. 9th report of the National Registry. Russian Journal of Transplantology and Artificial Organs. 2017;19(2):6-26. (In Russian). DOI:10.15825/1995-1191-2017-2-6-26 2. Vinogradov V.L. Actual issues of organ donation. Introduction. The lecture. Transplantologiya. The Russian Journal of Transplantation. 2013;(4):15-23. (In Russian).
3. Minina M.G. To some organizational aspects of organ donation. Russian Journal of Transplantology and Artificial Organs. 2010;12(3):81-88. (In Russian). DOI:10.15825/1995-1191-2010-3-81-88

4. Mironov A.A., Yaremin B.I., Kolsanov A.V., et al. Organ donation and transplantation coordination in the Samara region: Features of the regional model. Russian Journal of Transplantology and Artificial Organs. 2015;17(2):140-143. (In Russian). DOI:10.15825/1995-1191-2015-2-140-143
5. Серебряков И.Ю., Бадаев Ф.И., Климушева Н.Ф., Лещенко И.Г. Современное состояние донорской службы в Свердловской области. Вестник трансплантологии и искусственных органов. 2015;17(2):139. DOI:10.15825/1995-11912015-2-139-139

6. Николаев Г.В., Гордеев М.Л., Карпенко М.А. и др. Организационные аспекты органного донорства в Санкт-Петербурге. Вестник трансплантологии и искусственных органов. 2015;17(2):134-138. DOI:10.15825/1995-1191-2015-2-134-138
5. Serebryakov I.Yu., Badaev F.I., Klimusheva N.F., Leshchenko I.G. Current state of donor procurement service in the Sverdlovsk region. Russian Journal of Transplantology and Artificial Organs. 2015;17(2):139. (In Russian). DOI:10.15825/1995-1191-2015-2-139-139 6. Nikolaev G.V., Gordeev M.L., Karpenko M.A., et al. Organizational aspects of organ donation in St. Petersburg. Russian Journal of Transplantology and Artificial Organs. 2015;17(2):134-138. (In Russian). DOI:10.15825/1995-1191-2015-2-134-138 